\title{
An Evaluation of Total Disintegration Time for Three Different Doses of Sublingual Fentanyl Tablets in Patients with Breakthrough Pain
}

Srinivas Nalamachu

To view enhanced content go to www.paintherapy-open.com Received: March 8, 2013 / Published online: November 19, 2013

(C) The Author(s) 2013. This article is published with open access at Springerlink.com

\section{ABSTRACT}

Introduction: Breakthrough pain is common among patients with cancer and presents challenges to effective pain management. Breakthrough pain is characterized by rapid onset, severe intensity, and duration typically lasting $<1 \mathrm{~h}$. Thus, optimal relief from breakthrough pain is best attained by administering analgesics with dissolution times and bioavailabilities that closely match the onset and duration of breakthrough pain. The objective of this study was to assess complete disintegration time of three different doses of sublingual fentanyl tablets in opioid-tolerant patients.

Electronic supplementary material The online version of this article (doi:10.1007/s40122-013-0019-6) contains supplementary material, which is available to authorized users.

S. Nalamachu $(\bowtie)$

International Clinical Research Institute,

Leawood, KS, USA

e-mail: nalamachu@yahoo.com

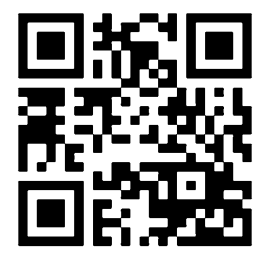

Enhanced content for this article is

available on the journal web site:

www.paintherapy-open.com
Methods: This was a single-center, nonrandomized, open-label study. Opioid-tolerant adult patients $(N=30)$ with chronic pain were assigned to one of three dose groups and selfadministered a single 100, 200, or $300 \mu \mathrm{g}$ sublingual fentanyl tablet (Abstral ${ }^{\circledR}$, Galena Biopharma, Portland, OR, USA). Time to complete disintegration was measured by each patient with a stopwatch and independently verified by study personnel.

Results: Disintegration time (mean $\pm \mathrm{SD}$ ) for sublingual fentanyl tablets (all doses) was $88.2 \pm 55.1 \mathrm{~s}$. Mean disintegration times tended to be slightly longer for the $200 \mu \mathrm{g}$ $(96.7 \pm 57.9 \mathrm{~s})$ and $300 \mu \mathrm{g}$ doses $(98.6 \pm 64.8 \mathrm{~s})$ compared to the $100 \mu \mathrm{g}$ dose $(69.5 \pm 40.5 \mathrm{~s})$. Differences were not statistically significant. Disintegration time was not significantly different between men and women and was not affected by age.

Conclusion: Sublingual fentanyl tablets dissolved rapidly (average time $<2 \mathrm{~min}$ ) in all patients, with the higher doses taking slightly more time to dissolve.

Keywords: Breakthrough pain; Dissolution time; Dwell time; Sublingual fentanyl tablets; Transmucosal immediate release fentanyl 


\section{INTRODUCTION}

Breakthrough pain is prevalent (41-95\%) among patients with cancer $[1,2]$ and presents challenges to effective pain management $[2,3]$. Breakthrough pain typically exhibits a rapid onset (typically $<5 \mathrm{~min}$, ranging from $1 \mathrm{~s}$ to 30 min until peak intensity), severe intensity, and lasts for $<1 \mathrm{~h}$, but may last for up to 1 to $2 \mathrm{~h}$ $[4,5]$. Therefore, optimal relief from breakthrough pain is best attained by administering analgesics which have pharmacokinetics and pharmacodynamics that closely match the time course of breakthrough pain events.

The transmucosal route of administration of analgesics can avoid first-pass hepatic metabolism and allow rapid entry of drugs into the systemic circulation [6, 7]. It can also yield increased bioavailability relative to orally administered drugs [8]. Current clinical guidelines recommend transmucosal fentanyl as an option for the relief of breakthrough cancer pain [9]. A variety of transmucosal fentanyl products with different routes of administration (e.g., lozenge, buccal tablet, buccal film, sublingual tablet, sublingual spray, and nasal spray) are available. A novel sublingual tablet form of fentanyl (Abstral ${ }^{\circledR}$; Galena Biopharma, Portland, OR, USA) was developed that would undergo rapid disintegration and absorption within the time of onset and duration of breakthrough pain [10].

The subjective nature of pain is reflected in the highly variable and individualized responses to pain therapies. Patient perception of "dwell time" contributes to preference, which in turn can affect compliance rates [11]. Previous studies have demonstrated the efficacy of sublingual fentanyl tablets in the treatment of breakthrough pain in patients who are opioid tolerant [12, 13]. Preliminary assessments of the disintegration time and patient acceptability of this fentanyl formulation have been previously presented [14-16]. Here, we present a detailed assessment of patient perception of the complete disintegration time of sublingual fentanyl tablets in practice-based, opioid-tolerant patients. Measurement of pain relief was not an objective of this study.

\section{METHODS}

\section{Study Population}

Men and women aged 18-75 years with chronic pain who were tolerant to opioids (i.e., morphine $\quad 60 \mathrm{mg} /$ day or equivalent for $\geq 1$ week) were eligible for enrollment in the study. Women of child-bearing potential had to be using an acceptable form of birth control to participate in the study. Exclusion criteria included: allergy to fentanyl or its derivatives; history of severe chronic obstructive pulmonary disease; or asthma that, in the investigator's opinion, was medically significant. Pregnant or lactating women and patients deemed by the investigator to be medically unstable were also excluded from the study.

\section{Study Design}

This single-center, non-randomized, open-label study was designed to enroll a minimum of 10 patients in each of 3 dose groups. The primary objective was to assess patient-reported time for complete disintegration of 3 different doses of sublingual fentanyl oral disintegrating tablets in opioid-tolerant patients. The design of the study was approved by an independent institutional review board (Ethical and Independent Review Committee, Inc., 
Independence, MO, USA) and the study was conducted in accordance with US Food and Drug Administration regulations for the conduct and monitoring of clinical investigations. Procedures were in accordance with Good Clinical Practice and International Conference on Harmonisation guidelines, and with the Declaration of Helsinki of 1975, as revised in 2000 and 2008. All patients provided written informed consent before initiation of study procedures.

During the training phase, patients were given a placebo matching the sublingual fentanyl tablet to ensure optimal sublingual placement of the tablet and to establish familiarity with the product dissolution and assessment of disintegration time. During the subsequent evaluation phase, each patient selfadministered a single 100, 200, or $300 \mu \mathrm{g}$ sublingual fentanyl tablet. Patients received the appropriate dose of study drug (as determined by the investigator) in an outpatient setting; all patients who were naive to rapid-acting fentanyl received sublingual fentanyl $100 \mu \mathrm{g}$. Patients being treated with other rapid-acting fentanyl products [e.g., Actiq $^{\circledR} \quad$ (fentanyl citrate oral transmucosal lozenge; Cephalon, Inc., Frazer, PA, USA), Fentora $^{\circledR}$ (fentanyl citrate buccal tablet; Cephalon, Inc., Frazer, PA, USA), or Onsolis ${ }^{\circledR}$ (fentanyl buccal soluble film; Meda Pharmaceuticals, Inc., Somerset, NJ, USA)] were given the equivalent of $50 \%$ of their dose at that time, to the nearest lower strength of sublingual fentanyl (not to exceed $300 \mu \mathrm{g}$ ).

Patients were permitted to use all concurrent medications, including long-acting opioids, for the duration of this study. However, patients were instructed not to use other forms of rapidacting fentanyl, including Actiq, Fentora, Onsolis, or Abstral, for breakthrough pain for $2 \mathrm{~h}$ before and after the administration of study drug [17-20]. Adherence to this requirement was independently confirmed by study personnel.

\section{Assessments}

Time to complete disintegration was defined as the time post-administration when the patient felt that the sublingual tablet had completely dissolved under the tongue, as measured by each patient with a stopwatch and independently verified by study personnel. Any adverse events (AEs) believed to be expected or unexpected, whether reported by the patient or noted by the investigator, were to be recorded.

\section{Statistical Methods}

Descriptive statistics were used to summarize pooled data from the individual treatment groups. Analyses were performed using Prism v5.04 (GraphPad Software, Inc., La Jolla, CA, USA). One-way analysis of variance (ANOVA), followed by the Bonferroni post hoc test, was used to compare the total disintegration times among the groups administered the 3 strengths of sublingual fentanyl. A 2-tailed unpaired $t$ test was used to assess the difference in disintegration time between men and women across all doses of sublingual fentanyl. Linear regression analysis was used to assess the effects of age on disintegration time across all doses of sublingual fentanyl.

\section{RESULTS}

\section{Demographics}

Pooled baseline demographics of patients in all treatment groups are summarized in Table 1. The mean age for all patients in this study was 
Table 1 Key baseline demographic characteristics

\begin{tabular}{lc}
\hline Characteristics & $\begin{array}{l}\text { Patients } \\
(\boldsymbol{N}=\mathbf{3 0})\end{array}$ \\
\hline Sex, $n(\%)$ & $12(40.0)$ \\
Men & $18(60.0)$ \\
Women & \\
Mean age, years (range) & $54(36-74)$ \\
All patients & $52(36-74)$ \\
Men & $56(38-74)$ \\
Women &
\end{tabular}

54 years (range $36-74$ years) with more women $(18 / 30 ; 60 \%)$ than men. Maintenance and breakthrough pain treatments for the study population are listed in Table 2.

\section{Disintegration Time of Sublingual Fentanyl}

The disintegration time (mean $\pm \mathrm{SD}$ ) for the sublingual placebo used during training was $107.1 \pm 73.4 \mathrm{~s}$. The disintegration time for sublingual fentanyl across all doses was $88.2 \pm 55.1 \mathrm{~s}$; there was a non-significant trend toward longer disintegration times for the 200 $\mu \mathrm{g}(96.7 \pm 57.9 \mathrm{~s})$ and $300 \mu \mathrm{g}(98.6 \pm 64.8 \mathrm{~s})$ sublingual fentanyl doses compared with the $100 \mu \mathrm{g}$ sublingual fentanyl dose $(69.5 \pm 40.5 \mathrm{~s}$; Fig. 1). Disintegration time for sublingual fentanyl across all doses was similar between men and women (Fig. 2), and was not affected by age (Fig. 3). No AEs occurred during the study.

\section{DISCUSSION}

The persistently high prevalence of breakthrough pain in patients with cancer indicates an ongoing need for rapidly acting analgesics with pharmacokinetic properties that
Table 2 Analgesic treatment history

Patients

$(N=30)$

Maintenance treatment, $n$ (\%)

Fentanyl transdermal system

$8(27)$

Methadone

Oxycodone controlled release

Fentanyl

$2(7)$

Hydrocodone and acetaminophen

$2(7)$

Hydromorphone extended release

$2(7)$

Morphine sulfate controlled release or

$2(7)$

extended release

Oxycodone

$2(7)$

Oxymorphone extended release

$2(7)$

Buprenorphine transdermal system

$1(3)$

Hydromorphone

$1(3)$

Pregabalin

$1(3)$

Tizanidine

$1(3)$

Breakthrough pain treatment, $n$ (\%)

Fentanyl buccal tablet

$12(40)$

Fentanyl oral transmucosal lozenge

Fentanyl sublingual tablet

Hydrocodone and acetaminophen

$2(7)$

Oxycodone

$2(7)$

Oxymorphone immediate release

Buprenorphine

Morphine sulfate extended release

Oxycodone and acetaminophen

Tramadol extended release

$1(3)$

match the rapid onset and short duration of breakthrough pain [21, 22]. Although several rapid-acting fentanyl analgesics [Abstral, Actiq, Fentora, Onsolis, Subsys ${ }^{\circledR}$ (fentanyl sublingual spray; INSYS Therapeutics, Inc., Chandler, AZ, USA), and Lazanda $^{\circledR}$ (fentanyl nasal spray; Depomed, Newark, CA, USA)] are currently 


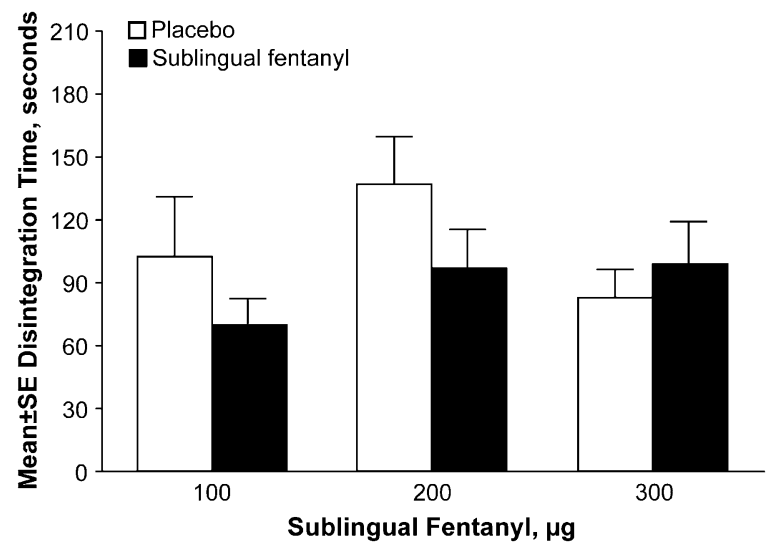

Fig. 1 Complete disintegration time of sublingual fentanyl as a function of dose. One-way analysis of variance among 3 dose groups of sublingual fentanyl $(P=0.4313)$

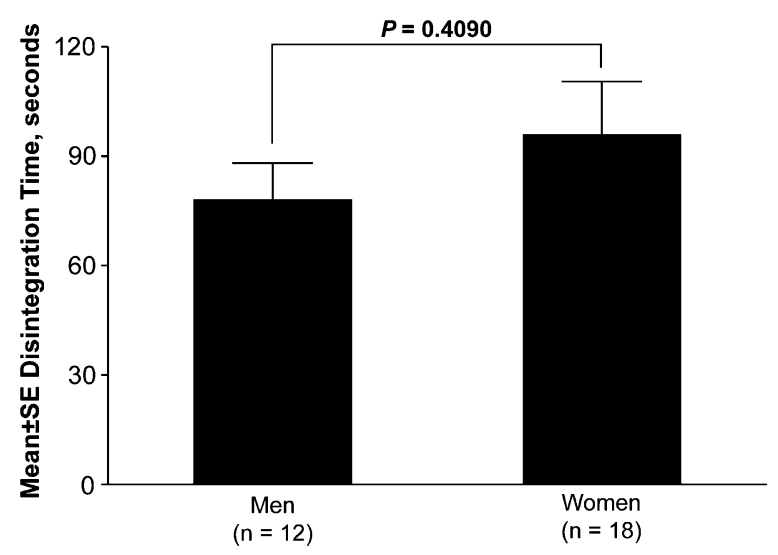

Fig. 2 Complete disintegration time of sublingual fentanyl as a function of sex (unpaired $t$ test, $P=0.4090$ )

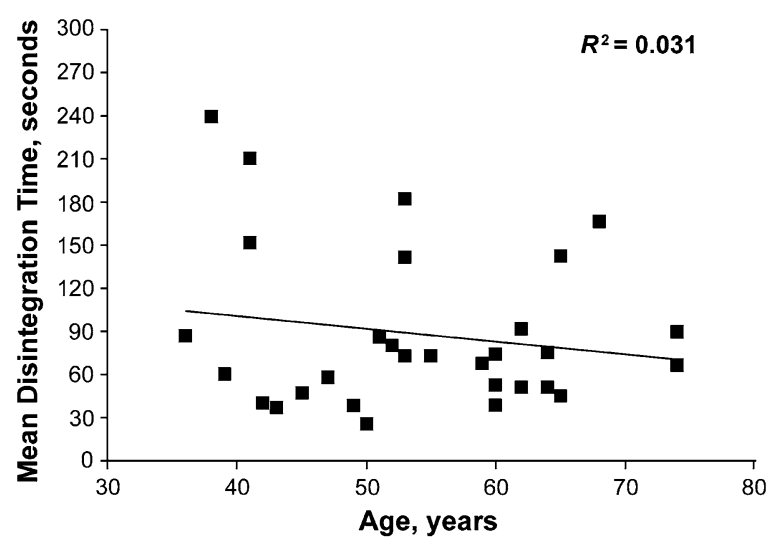

Fig. 3 Complete disintegration time of sublingual fentanyl as a function of age (linear regression, $P=0.3552$ ) available, these products are not therapeutically interchangeable, and there may be considerable differences in patient preferences [17-20, 23, 24]. Sublingual fentanyl, with a novel mucoadhesive, is an effective analgesic for the management of breakthrough cancer pain [12, 13]. In the present study, sublingual fentanyl exhibited rapid disintegration times and high levels of bioavailability consistent with the ease of administration of this form of fentanyl.

Perceptions of disintegration time (or "dwell time") could be a factor in patient preference, although direct evidence is currently lacking. Several earlier generation fentanyl products currently used for the relief of breakthrough pain employ different methods of drug delivery (e.g., lozenge, buccal tablet, film) and should be held in the mouth for approximately 15-30 min to achieve drug dissolution [17-19]. These relatively long dwell times may not be optimal for the relief of breakthrough pain. The present study assessed the patient's perception of complete disintegration time and taste of 3 doses $(100,200$, or $300 \mu \mathrm{g})$ of rapid-acting sublingual fentanyl. The results showed that sublingual fentanyl rapidly disintegrated, with the time to patient-reported complete disintegration ranging from $69.5 \mathrm{~s}$ in the 100 $\mu \mathrm{g}$ dose group to $98.6 \mathrm{~s}$ in the $300 \mu \mathrm{g}$ dose group. Although there were no significant differences in disintegration time between sublingual fentanyl dose groups, this study was not powered for statistical analysis. The mean disintegration time across all doses of sublingual fentanyl did not differ significantly by age or sex. Patients in this study were exposed to placebo tablet training prior to sublingual fentanyl administration. Using a sublingual placebo tablet to familiarize patients with optimal placement of the drug and perception of its complete disintegration may be a useful component of individualized 
care in the management of breakthrough cancer pain [25].

Effective treatment of breakthrough cancer pain may be influenced by patient acceptance of the drug, and it is important to note that the present study focused on disintegration time and not pain relief. In addition, the open-label, nonrandomized design of this study limits the conclusions that can be drawn. Furthermore, the study did not include crossover to a comparator treatment such as a matching placebo sublingual tablet or a different transmucosal fentanyl product. Finally, the small sample size of this study may not have provided adequate statistical power to detect differences between groups. Therefore, additional studies are needed to assess the degree to which disintegration time is of practical importance in the willingness of patients to switch from their current treatment to sublingual fentanyl.

\section{CONCLUSIONS}

Sublingual fentanyl tablets of all doses dissolved rapidly, with an average time to complete disintegration of $<2 \mathrm{~min}$. This compares very favorably to other solid forms of transmucosal immediate release fentanyl, each having dwell times of approximately 15-30 min until complete disintegration.

\section{ACKNOWLEDGMENTS}

These data were reported in part in a poster presentation at the 6th World Congress of the World Institute of Pain, February 4-6, 2012, in Miami Beach, FL, USA, and at the International Association for the Study of Pain 14th World Congress on Pain, August 27-31, 2012, in Milan, Italy. Rahul Nalamasu and Keerti Uppalapati provided assistance with conducting the study.
This research was funded by ProStrakan Inc., Bridgewater, NJ, USA. Craig Albright, PhD, and John Decker, PhD, of Complete Healthcare Communications, Inc., Chadds Ford, PA, USA, provided editorial support for the development of this manuscript with funding from ProStrakan Inc. and Galena Biopharma, Portland, OR, USA. Dr. Nalamachu is the guarantor for this article, and takes responsibility for the integrity of the work as a whole.

Conflict of interest. Srinivas R. Nalamachu reports that he is a consultant, serves on the advisory board, and receives/d honoraria from Galena, ProStrakan, Cephalon (now Teva), Endo Pharmaceuticals (now Endo Health Solutions), Lilly, Nuvo, Archimedes Pharma, Insys, Ipsen, Grünenthal, Myoscience, and Covidien. He also reports that he was on the speakers' bureau for Cephalon (now Teva), Lilly, Archimedes Pharma, Ipsen, and Covidien.

Compliance with ethics guidelines. The design of the study was approved by an independent institutional review board (Ethical and Independent Review Committee Inc., Independence, MO, USA) and the study was conducted in accordance with US Food and Drug Administration regulations for the conduct and monitoring of clinical investigations. Procedures were in accordance with Good Clinical Practice and International conference on Harmonisation guidelines, and with the Declaration of Helsinki of 1975, as revised in 2000 and 2008. All patients provided written informed consent before initiation of study procedures.

Open Access. This article is distributed under the terms of the Creative Commons Attribution Noncommercial License which permits any noncommercial use, distribution, and reproduction in any medium, provided the original author(s) and the source are credited. 


\section{REFERENCES}

1. Svendsen KB, Andersen S, Arnason $\mathrm{S}$, et al. Breakthrough pain in malignant and nonmalignant diseases: a review of prevalence, characteristics and mechanisms. Eur J Pain. 2005;9:195-206.

2. Webster LR. Breakthrough pain in the management of chronic persistent pain syndromes. Am J Manag Care. 2008;14:S116-22.

3. Breivik H, Cherny N, Collett B, et al. Cancer-related pain: a pan-European survey of prevalence, treatment, and patient attitudes. Ann Oncol. 2009;20:1420-33.

4. Portenoy RK, Payne D, Jacobsen P. Breakthrough pain: characteristics and impact in patients with cancer pain. Pain. 1999;81:129-34.

5. Zeppetella G, O'Doherty CA, Collins S. Prevalence and characteristics of breakthrough pain in cancer patients admitted to a hospice. J Pain Symptom Manag. 2000;20:87-92.

6. Gizurarson S. Anatomical and histological factors affecting intranasal drug and vaccine delivery. Curr Drug Deliv. 2012;9:566-82.

7. Zhang H, Zhang J, Streisand JB. Oral mucosal drug delivery: clinical pharmacokinetics and therapeutic applications. Clin Pharmacokinet. 2002;41:661-80.

8. Vasisht N, Gever LN, Tagarro I, Finn AL. Formulation selection and pharmacokinetic comparison of fentanyl buccal soluble film with oral transmucosal fentanyl citrate: a randomized, open-label, single-dose, crossover study. Clin Drug Investig. 2009;29:647-54.

9. National Comprehensive Cancer Network. NCCN Clinical Practice Guidelines in Oncology. Adult Cancer Pain. Version 1.2013. 2013. http://www. nccn.org/professionals/physician_gls/pdf/pain.pdf. Accessed 18 Feb 2013.

10. Abstral (fentanyl sublingual tablets for breakthrough cancer pain). P\&T. 2011;36:2-28.

11. Douroumis D. Orally disintegrating dosage forms and taste-masking technologies; 2010. Expert Opin Drug Deliv. 2011;8:665-75.

12. Rauck RL, Tark M, Reyes E, et al. Efficacy and longterm tolerability of sublingual fentanyl orally disintegrating tablet in the treatment of breakthrough cancer pain. Curr Med Res Opin. 2009;25:2877-85.
13. Nalamachu S, Hassman D, Wallace MS, Dumble S, Derrick R, Howell J. Long-term effectiveness and tolerability of sublingual fentanyl orally disintegrating tablet for the treatment of breakthrough cancer pain. Curr Med Res Opin. 2011;27:519-30.

14. Nalamachu S, Ruck D, Fassbinder S, Akright C. An evaluation of total disintegration time for 3 different doses of sublingual fentanyl tablets. World Institute of Pain 6th World Congress; 2012 Feb 4-6; Miami Beach, FL

15. Lennernas B, Frank-Lissbrant I, Lennernas $H$, Kalkner KM, Derrick R, Howell J. Sublingual administration of fentanyl to cancer patients is an effective treatment for breakthrough pain: results from a randomized phase II study. Palliat Med. 2010;24:286-93.

16. Nalamachu S, Fassbinder S, Nalamasu R. An evaluation of taste and preference for 3 different doses of sublingual fentanyl tablets. International Association for the Study of Pain 14th World Congress on Pain; 2012 Aug 27-31; Milan, Italy

17. Actiq $^{\circledR}$ (fentanyl citrate oral mucosal lozenge). Full Prescribing Information, Cephalon Inc., Salt Lake City, UT, 2011.

18. Fentora ${ }^{\circledR}$ (fentanyl buccal tablet). Full Prescribing Information, Cephalon, Inc., Salt Lake City, UT, 2011.

19. Onsolis $^{\circledR}$ (fentanyl buccal soluble film). Full Prescribing Information, Meda Pharmaceuticals, Inc., Somerset, NJ, 2009.

20. Abstral $^{\circledR}$ (fentanyl sublingual tablet). Full Prescribing Information, ProStrakan Inc., Bridgewater, NJ, 2012.

21. Caraceni A, Bertetto O, Labianca R, et al. Episodic (breakthrough) pain prevalence in a population of cancer pain patients. Comparison of clinical diagnoses with the QUDEI-Italian questionnaire for intense episodic pain. J Pain Symptom Manag. 2012;43:833-41.

22. Manchikanti L, Singh V, Caraway DL, Benyamin RM. Breakthrough pain in chronic non-cancer pain: fact, fiction, or abuse. Pain Physician. 2011;14: E103-17.

23. Lazanda ${ }^{\circledR}$ (fentanyl nasal spray CII). Full Prescribing Information, Archimedes Pharma US Inc, Bedminster, NJ, 2011.

24. Subsys ${ }^{\circledR}$ (fentanyl sublingual spray). Full Prescribing Information, INSYS Therapeutics, Inc., Phoenix, AZ, 2012. 
25. England R, Maddocks M, Manderson C, ZadoraChrzastowska S, Wilcock A. How practical are transmucosal fentanyl products for breakthrough cancer pain? Novel use of placebo formulations to survey user opinion. BMJ Support Palliat Care. 2011;1:349-51. 